9 - ORIGINAL ARTICLE

TECHNICAL SKILL

\title{
Technique for implanting intramuscular electrodes in the diaphragm by videolaparoscopy in pigs ${ }^{1}$
}

\author{
Rodrigo Guellner Ghedini ${ }^{\mathrm{I}}$, Artur de Oliveira Paludo ${ }^{\mathrm{II}}$, Rodrigo Mariano ${ }^{\mathrm{II}}$, Éverton Franco Silva ${ }^{\mathrm{II}}$, Leonardo Dalla Giacomassa \\ Rocha Thomaz ${ }^{\text {II }}$ Gustavo DiehI ${ }^{\text {II }}$ Lucas Elias Lise Simoneti" ${ }^{\text {II }}$ Igor Pires Drachler", Cristiano Feijó Andrade ${ }^{\mathrm{III}}$
}

DOI: http://dx.doi.org/10.1590/S0102-865020160020000009

IFellow PhD degree, Postgraduate Program in Pneumological Science, Universidade Federal do Rio Grande do Sul (UFRGS), Porto Alegre-RS, Brazil. Conception, design, intellectual and scientific content of the study; acquisition and interpretation of data; manuscript writing.

${ }^{\mathrm{II} G r a d u a t e ~ s t u d e n t, ~ H o s p i t a l ~ d e ~ C l i ́ n i c a s ~ d e ~ P o r t o ~ A l e g r e ~(H C P A), ~ P o r t o ~ A l e g r e-R S, ~ B r a z i l . ~ T e c h n i c a l ~ p r o c e d u r e s . ~}$

IIIPhD, HCPA, Hospital da Criança Santo Antônio, Porto Alegre-RS, Brazil. Design of the study, acquisition and analysis of data, manuscript writing, English version, supervised all phases of the study.

\begin{abstract}
PURPOSE: To describe a novel approach for implanting intramuscular electrodes in the diaphragm through videolaparoscopy.

METHODS: We used twelve pigs for this videolaparoscopic technique, which permits at the same time to explore the diaphragm, to locate its motor points and to fix the electrodes in the diaphragm bilaterally. In this technique we used three trocars: one portal for a 10$\mathrm{mm} 0^{\circ}$ viewing angle laparoscope, one portal for the manipulation of structures and another for electrode implantation.

RESULTS: All animals survived the procedure without pneumothorax/capnothorax or other complication. Implanted electrodes provided an appropriate interface between the muscle and the electrical current generator, and electroventilation was satisfactorily generated in all animals.
\end{abstract}

CONCLUSION: This videolaparoscopic technique with three trocars enables the exploration and identification of motor points and an efficient fixation of one or two electrodes in each hemidiaphragm.

Key words: Laparoscopy. Diaphragm. Pacemaker, Artificial. Swine. 


\section{Introduction}

Electroventilation has been used in patients with significant impairment of diaphragmatic function and chronic dependence on mechanical ventilation, such as those with high cervical injury (C1-C5), hypoventilation syndrome, amyotrophic lateral sclerosis (ALS) and others ${ }^{1-4}$.

Initially, Glenn described the diaphragm activation with implantation of electrodes directly on the thoracic phrenic nerve $\mathrm{e}^{5,6}$, which was later refined by other researchers ${ }^{7,8}$. Even when successful, this technique is not free to cause permanent damage to the phrenic nerve due to the electrode placement procedure ${ }^{9}$. This technique can be performed through either a unilateral or bilateral thoracotomy or thoracoscopy.

The implantation of electrodes directly into the diaphragm in its abdominal portion has emerged as an effective and safe alternative where electrodes are implanted into the muscle through videolaparoscopy and are connected to a diaphragmatic pacemaker system (DPS $)^{8-12}$. The first experiments were performed placing the electrode using either by laparotomy ${ }^{13}$ or laparoscopy, which showed that transdiaphragmatic pressures and tidal volumes resulting from intramuscular electrodes were comparable to those obtained with the phrenic nerve stimulation ${ }^{8,9,14}$. This procedure consists of locating the motor point of the muscle or functional points corresponding to the muscle area where the branches of the phrenic nerve penetrate into the diaphragm ${ }^{10,15,16}$, avoiding the need for direct manipulation of the phrenic nerve ${ }^{17}$. In all cases, the phrenic nerve must be preserved with its function for proper operation of the diaphragmatic pacemaker ${ }^{18-21}$.

Electrical stimulation of the diaphragm has allowed for a better quality of life, in addition to allowing for weaning from mechanical ventilation, decreasing the frequency of respiratory infections and reducing the amount spent on health-related $\operatorname{costs}^{22,23}$.

This article aims to describe a procedure involving electrode implantation directly into the diaphragm muscle in the abdominal portion through videolaparoscopy in pigs.

\section{Methods}

The Research Ethics Committee of the Hospital de Clínicas de Porto Alegre approved this study under \#10260.

Electrodes were implanted in the abdominal portion of 12 Large White pigs, weighing $25-30 \mathrm{~kg}$, treated according to the Ethical Code for Animal Experimentation of the World Health Organization ${ }^{24}$. Initially, the animals received an intramuscular premedication with ketamine $20 \mathrm{mg} / \mathrm{kg}$, midazolam $0.8 \mathrm{mg} / \mathrm{kg}$ meperidine and $5 \mathrm{mg} / \mathrm{kg}$, followed by peripheral vein catheterization. Anesthesia was induced with $5 \mathrm{mg} / \mathrm{kg}$ intravenous propofol followed by tracheal intubation and mechanical ventilation with positive pressure (Nikkei - Takaoka, São Paulo, Brazil), maintained with a continuous infusion of propofol $(0.2-$ $0.4 \mathrm{mg} / \mathrm{kg}$ ) and a bolus of phentanyl $100 \mu \mathrm{g}$. Neuromuscular blocker was not used at any time during the procedure. Body temperature and ECG were monitored throughout the surgery.

The surgery was performed using aseptic methods. The animals were kept in a supine position, and then surgical drapes were aseptically placed for performing videolaparoscopy. Initially, a conventional Veress needle was inserted for insufflation of the abdomen with $\mathrm{CO}_{2}$. The approach used through three incisions in the abdominal wall for insertion of $10 \mathrm{~mm}$ trocaters, an supraumbilical region for insertion of a $0^{\circ}$ viewing angle laparoscope and other two $10 \mathrm{~mm}$ trocaters, one in the left and other in the right side for insertion of the laparoscopic instruments (Figure 1A).

Both the right and left hemidiaphragm were bilaterally explored to locate the motor point, using an electrode attached to an endoscopic instrument developed by our group (Figure 2A). The exploration of the muscle was guided using anatomical landmarks of the abdominal portion of the diaphragm. Electrical stimuli were applied with a current of $8 \mathrm{~mA}$ intensity and a pulse width of $300 \mathrm{~ms}$ for selecting places where a global muscle contraction was observed (Figure 2 B,C). When were used two electrodes on each side of the diaphragm (anterior and posterior portion) we observed a better muscle contraction compared with the use of one electrode in each hemidiaphragm. The electrode implantation was performed at the same time that the site was defined, and this was only possible due to the electrode characteristics and the deployment tool developed by our group.

In 12 animals, four electrodes were implanted in the abdominal surface of the diaphragm, two on each side (anterior and posterior portion). The falciform ligament release was required, in addition to the use of a liver retractor, for a better view of the posterior portion of the diaphragm (Figure 2D). Laparoscopic trocaters were removed under direct vision and the closure of the abdominal wall was performed in layers. The wires of the electrodes were placed in the subcutaneous tissue of the abdominal wall for later access (Figure 1B). 


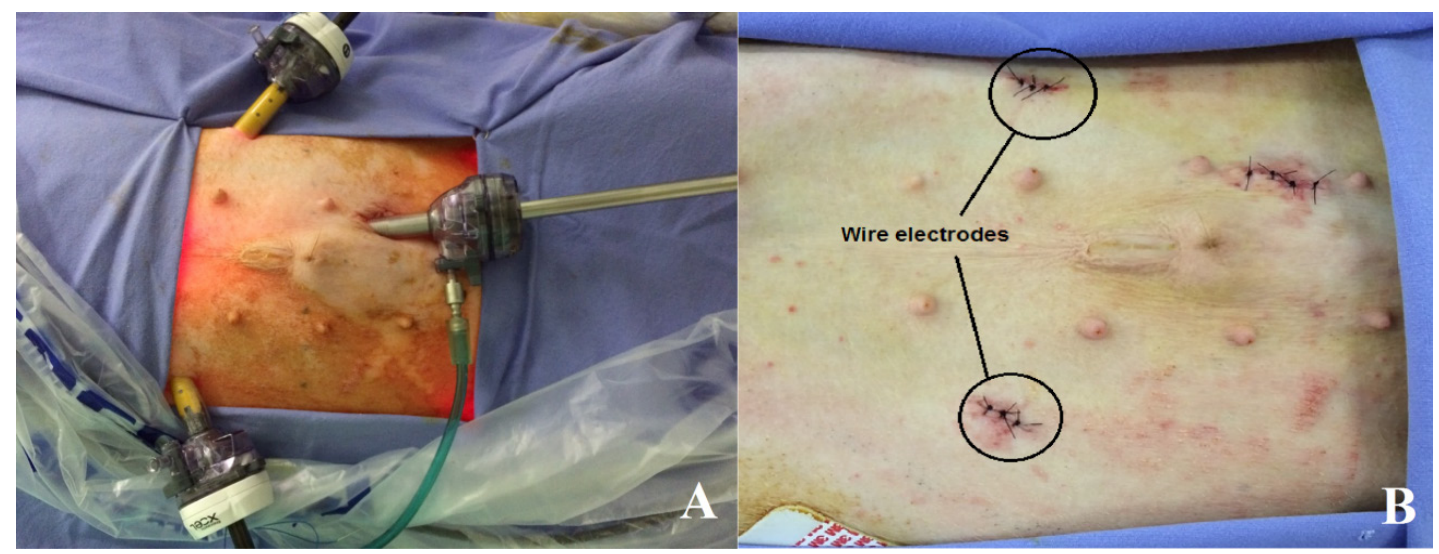

FIGURE 1 - (A) Trocar placement in the abdominal region of the pig; (B) Lead wire electrodes housed in the subcutaneous abdominal wall.

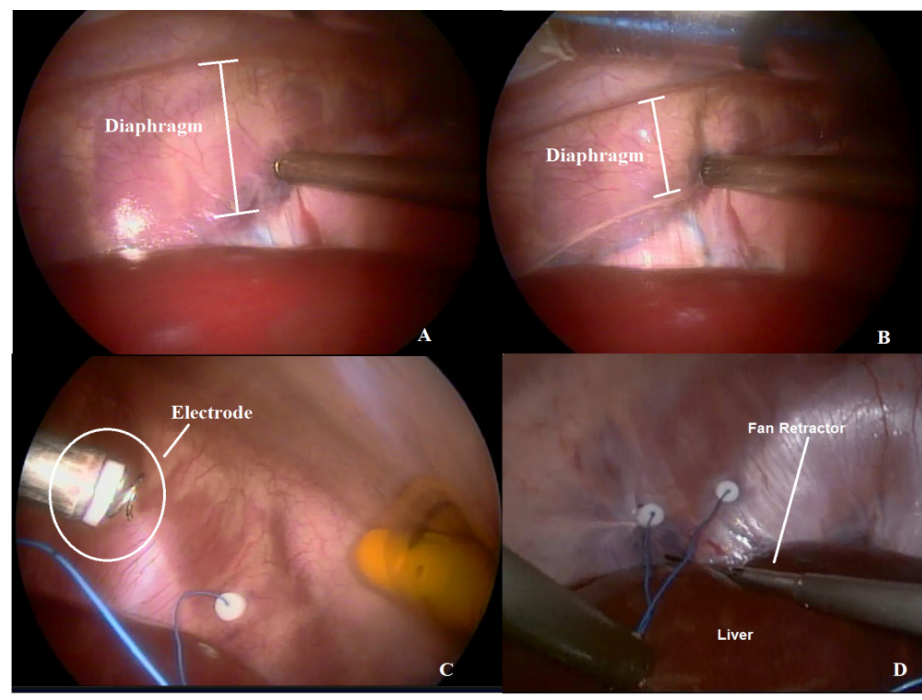

FIGURE 2 - (A) Exploiting Diaphragm with deployment device; (B) Muscle contraction during electrical stimulation; (C) Aspect of the electrode before implantation; (D) Liver retractor used for better visualization of the right hemidiaphragm.

After finishing the surgical procedure, the animals were kept under observation for 15 days at a specific location for animal care. After this observation period, the animals were anesthetized and intubated following the same previously described protocol. The wires placed in the subcutaneous tissue of the abdominal wall were exposed, and then connected to a current generator for the evaluation of muscular contraction and proper electrode attachment to the diaphragm. All animals were euthanized with an overdose of the anesthetic propofol, followed by lethal intravenous injection of potassium chloride after six hours of diaphragmatic stimulation. The diaphragm was removed for subsequent morphological evaluation.

\section{Results}

The use of three trocars proved to be sufficient for a laparoscopic approach to the implantation of the intramuscular electrodes in the abdominal portion of the diaphragm. The average time spent on the procedure was 85 minutes. All animals survived the procedure, and only one animal had small hemorrhage due to a liver laceration during the implantation of the electrodes, but there were no clinical consequences. There was no pneumothorax during deployment that would undermine the achievement of electroventilation. The electrodes and laparoscopic deployment tool that the group developed provided an easy approach for use during the procedure. The diaphragm post-mortem evaluation enabled us to verify the electrode positioning, as well as its attachment to the muscle. All leads were properly fixed to the muscle without any evidence of muscle damage allowing for an appropriate interface for the electrical conduction.

\section{Discussion}

Diaphragmatic electrical stimulation using intramuscular electrodes is an approach to electroventilation, which has the ability to provide ventilation in the absence of spontaneous inspiratory activity. The implantation of electrodes in the abdominal portion of the diaphragm using laparoscopy is a minimally invasive and safe technique for this purpose ${ }^{2,24}$. The correct location of the electrode implantation point in the diaphragm is associated with better performance in the recruitment of muscle fibers ${ }^{14,16,19}$. The scanning technique allows for muscle mapping and the observation of muscle contractions occurring in several different places in the muscle. Despite the anatomical difference between the motor and functional points, the direct muscle contraction visualization technique can be used to determine the implantation place for electrodes in the diaphragm ${ }^{14}$.

Intramuscular electrodes were implanted in the diaphragm without the occurrence of pneumothorax or capnotórax. Even where we observe muscle transfixation, no pulmonary injury 
or pneumoperitoneum leaking into the pleural space caused respiratory failure or difficulty in ventilation. Pneumoperitoneum is generated by pressurized $\mathrm{CO}_{2}$ in the abdominal cavity and may cause pneumothorax resulting in clinical repercussion in only $4 \%$ of the cases. The incidence of this situation is around $42 \%$ in humans ${ }^{25}$. In reports using more sensitive tests such as computed tomography, researchers have observed an incidence of gas in the chest cavity at a rate of $85 \%$ for laparoscopic procedures in general $^{25}$. In human studies where electrodes were implanted in the diaphragm, researchers reported the occurrence of pneumothorax during and after surgery ${ }^{24}$. In another report, the most common complication observed in patients was capnotórax, which was most likely related to the electrode implantation procedure ${ }^{26}$.

In a pilot study, we conducted the implantation of electrodes in the diaphragm of rabbits through laparoscopy with the use of four portals. However, we found that the procedure was feasible with only three trocars. Moreover, with this arrangement of the trocars the identification of motor points was possible for each hemi-cupula, as well as their immediate implanting. Several studies have demonstrated the use of four trocars to perform this procedure in animals ${ }^{14,17}$ and humans $s^{2,21,24}$.

An average time of 85 minutes was spent on the procedure, which is relatively low, even when two electrodes were implanted in each hemi diaphragm. Some researchers report mean operative times varying from 150 to 98 minutes $^{27,28}$.

\section{Conclusions}

The approach of the diaphragm is feasible by videolaparoscopy using only three trocars for the implantation of two intramuscular electrodes in each hemidiaphragm. The use of two electrodes per hemidiaphragm generated a global muscle contraction enough to produce pulmonary ventilation. The use of a deployment device for the electrodes during surgery that identifies the motor points of the diaphragm and at the same time fix the electrodes to the muscle probably reduced our surgical time.

\section{References}

1. Glenn WW, Holcomb WG, Gee JB, Rath R. Central hypoventilation: long-term ventilatory assistance by radiofrequency electrophrenic respiration. Ann Surg. 1970;172(4):755-73. PMID: 5458627.

2. Onders RP, Elmo M, Khansarinia S, Bowman B, Yee J, Road J, Bass B, Dunkin B, Ingvarsson PE, Oddsdóttir M. Complete worldwide operative experience in laparoscopic diaphragm pacing: results and differences in spinal cord injured patients and amyotrophic lateral sclerosis patients. Surg Endosc. 2009;23(7):1433-40. PMID: 19067067.

3. Sardenberg RA, Secaf LB, Pinotti AC, Taricco MA, Brock RS, Younes RN. Diaphragmatic pacing: unusual indication with successful application. J Bras Pneumol. 2011;37(5):697-9. PMID: 22042405.

4. Onders RP. Functional electrical stimulation: restoration of respiratory function. Handb Clin Neurol. 2012;109:275-82. PMID: 23098719.

5. Glenn WW, Furman S, Gordon AJ, Escher DJ, Van Heeckeren DW. Radiofrequency-controlled catheter pacemaker. Clinical application. N Engl J Med. 1966;275(3):137-40. PMID: 5938859.

6. van Heeckeren DW, Glenn WW. Electrophrenic respiration by radiofrequency induction. J Thorac Cardiovasc Surg. 1966;52(5):655-65. PMID: 5955177.

7. Thoma H, Gerner H, Holle J, Kluger P, Mayr W, Meister B, Schwanda G, Stöhr H. The phrenic pacemaker. Substitution of paralyzed functions in tetraplegia. ASAIO Trans. 1987;33(3):472-9. PMID: 3675976.

8. Peterson DK, Nochomovitz ML, Stellato TA, Mortimer JT. Longterm intramuscular electrical activation of the phrenic nerve: efficacy as a ventilatory prosthesis. IEEE Trans Biomed Eng. 1994;41(12):1127-35. PMID: 7851914.

9. Peterson DK, Nochomovitz ML, Stellato TA, Mortimer JT. Longterm intramuscular electrical activation of the phrenic nerve: safety and reliability. IEEE Trans Biomed Eng. 1994;41(12):1115-26. PMID: 7851913.

10. Nochomovitz ML, Dimarco AF, Mortimer JT, Cherniack NS. Diaphragm activation with intramuscular stimulation in dogs. Am Rev Respir Dis. 1983;127(3):325-9. PMID: 6830053.

11. DiMarco AF, Onders RP, Ignagni A, Kowalski KE. Inspiratory muscle pacing in spinal cord injury: case report and clinical commentary. J Spinal Cord Med. 2006;29(2):95-108. PMID: 16739553.

12. Nikfarjam M, Story DA, Nunn A, Howard M. Direct diaphragm pacing stimulation. ANZ J Surg. 2011;81(7-8):496-8. PMID: 22023090.

13. Ghedini RG, Margarites A, Felix EA, Xavier RG, Andrade CF. Development of a new experimental model of intramuscular electrical stimulation of the diaphragm in rabbits. Acta Cir Bras. 2010;25(6):475-8. PMID: 21120276.

14. Schmit BD, Stellato TA, Miller ME, Mortimer JT. Laparoscopic placement of electrodes for diaphragm pacing using stimulation to locate the phrenic nerve motor points. IEEE Trans Rehabil Eng. 1998;6(4):382-90. PMID: 9865885.

15. Peterson DK, Nochomovitz M, DiMarco AF, Mortimer JT. Intramuscular electrical activation of the phrenic nerve. IEEE Trans Biomed Eng. 1986;33(3):342-51. PMID: 3957387.

16. Ghedini RG, Espinel JO, Felix EA, Paludo AO, Mariano R, Holand AR, Andrade CF. Effectiveness of diaphragmatic stimulation with single-channel electrodes in rabbits. J Bras Pneumol. 2013;39(4):490-4. PMID: 24068272.

17. Aiyar H, Stellato TA, Onders RP, Mortimer JT. Laparoscopic implant instrument for the placement of intramuscular electrodes in the diaphragm. IEEE Trans Rehabil Eng. 1999;7(3):360-71. PMID: 10498381.

18. DiMarco AF, Onders RP, Kowalski KE, Miller ME, Ferek S, Mortimer JT. Phrenic nerve pacing in a tetraplegic patient via intramuscular diaphragm electrodes. Am J Respir Crit Care Med. 2002;166(12 Pt 1):1604-6. PMID: 12471076.

19. Onders RP, Dimarco AF, Ignagni AR, Aiyar H, Mortimer JT. Mapping the phrenic nerve motor point: the key to a successful laparoscopic diaphragm pacing system in the first human series. Surgery. 2004;136(4):819-26. PMID: 15467667.

20. DiMarco AF, Onders RP, Ignagni A, Kowalski KE, Mortimer JT. Phrenic nerve pacing via intramuscular diaphragm electrodes in tetraplegic subjects. Chest. 2005;127(2):671-8. PMID: 15706014. 
21. Posluszny JA Jr, Onders R, Kerwin AJ, Weinstein MS, Stein DM, Knight J, Lottenberg L, Cheatham ML, Khansarinia S, Dayal S, Byers PM, Diebel L. Multicenter review of diaphragm pacing in spinal cord injury: successful not only in weaning from ventilators but also in bridging to independent respiration. J Trauma Acute Care Surg. 2014;76(2):303-9; discussion 9-10. PMID: 24458038.

22. Stellato TA, Peterson DK, Buehner P, Nochomovitz ML, Mortimer JT. Taking the laparoscope to the laboratory for ventilatory research. Am Surg. 1990;56(3):131-3. PMID: 2138441.

23. Anderson KD. Targeting recovery: priorities of the spinal cordinjured population. J Neurotrauma. 2004;21(10):1371-83. PMID: 15672628

24. Tedde ML, Onders RP, Teixeira MJ, Lage SG, Ballester G, Brotto MW, Okumura EM, Jatene FB. Electric ventilation: indications for and technical aspects of diaphragm pacing stimulation surgical implantation. J Bras Pneumol. 2012;38(5):566-72. PMID: 23147048.

25. Clements RH, Reddy S, Holzman MD, Sharp KW, Olsen D, Holcomb GW, Richards WO. Incidence and significance of pneumomediastinum after laparoscopic esophageal surgery. Surg Endosc. 2000;14(6):553-5. PMID: 10890964.

26. Tedde ML, Vasconcelos Filho P, Hajjar LA, de Almeida JP, Flora GF, Okumura EM, Osawa EA, Fukushima JT, Teixeira MJ, Galas FR, Jatene FB, Auler JO Jr. Diaphragmatic pacing stimulation in spinal cord injury: anesthetic and perioperative management. Clinics (Sao Paulo). 2012;67(11):1265-9. PMID: 23184201

27. Onders RP, Elmo MJ, Ignagni AR. Diaphragm pacing stimulation system for tetraplegia in individuals injured during childhood or adolescence. J Spinal Cord Med. 2007;30 Suppl 1:S25-9. PMID: 17874683 .

28. Onders RP, Elmo M, Kaplan C, Katirji B, Schilz R. Final analysis of the pilot trial of diaphragm pacing in amyotrophic lateral sclerosis with long-term follow-up: diaphragm pacing positively affects diaphragm respiration. Am J Surg. 2014;207(3):393-7; discussion 7.

PMID: 24439161.

\section{Correspondence:}

Cristiano Feijó Andrade

Hospital de Clínicas de Porto Alegre, Serviço de Cirurgia Torácica

Rua Ramiro Barcelos, 2.350

90035-903 Porto Alegre - RS Brasil

Tel.: (55 51)3359-8684

Fax: (55 51)3359-8884

cristianofa@gmail.com

Received: Oct 5, 2015

Review: Dec 11, 2015

Accepted: Jan 12, 2016

Conflict of interest: none

Financial sources: FIPE and FAPERGS

${ }^{1}$ Research performed at Animal Experimentation Unit Research Center, Airway and Lung Laboratory, Hospital de Clínicas de Porto Alegre (HCPA), RS, Brazil. 